\title{
Osteopathy in Germany: attitudes, beliefs and handling among general practitioners - results of a nationwide cross-sectional questionnaire survey
}

\author{
Gordian L. Schmid ${ }^{1{ }^{*}}$, Jeremias Kluge ${ }^{1 \dagger}$, Tobias Deutsch ${ }^{1}$, Anne-Kathrin Geier ${ }^{1}$, Markus Bleckwenn ${ }^{1}$,
} Susanne Unverzagt ${ }^{2 \dagger}$ and Thomas Frese ${ }^{2 \dagger}$

\begin{abstract}
Background: Osteopathy is a type of complementary medicine based on specific manual techniques. In many countries, including Germany, the profession is not officially regulated, and evidence for the effectiveness of osteopathy is insufficient for most diseases. Nevertheless, many health insurances in Germany offer reimbursement for therapy costs, if osteopathy is recommended by a physician.

This cross-sectional survey of German general practitioners (GPs) explored beliefs and attitudes towards osteopathic medicine and described their daily interactions with it.

Methods: A random sample of 1000 GPs from all federal states was surveyed by mail using a self-designed questionnaire. We collected data on sociodemographics, personal experiences with osteopathy, and attitudes and expectations towards osteopathy. In particular, participants were asked about indications for osteopathic treatment and their beliefs about its effectiveness for different patient groups and diagnoses. A self-designed score was used to estimate general attitudes towards osteopathy and identify factors correlated with greater openness. Additionally, we performed logistic regression to reveal factors associated with the frequency of recommending osteopathy to patients.

Results: Response rate was $34.4 \% .46 .5 \%$ of participants were women, and the median age was 56.0 years. $91.3 \%$ of GPs had referred patients to an osteopath, and $88.0 \%$ had recommended osteopathy to their patients. However, $57.5 \%$ acknowledged having little or no knowledge about osteopathy. Most frequent reasons for a recommendation were spinal column disorders (46.2\%), other complaints of the musculoskeletal system (18.2\%) and headaches (9.8\%). GPs estimated the highest benefit for chronically ill and middle-aged adults. Female gender (OR 2.09; $95 \% \mathrm{Cl}$ 1.29-3.38) and personal treatment experiences (OR $5.14 ; 95 \% \mathrm{Cl} 2.72-9.72)$ were independently positively associated with more frequent treatment recommendation.
\end{abstract}

*Correspondence: gordian.schmid@posteo.de

${ }^{\dagger}$ Gordian L. Schmid and Jeremias Kluge shared first authorship, both

authors contributed equally to this work.

${ }^{\dagger}$ Susanne Unverzagt and Thomas Frese shared last authorship.

1 Department of General Practice, Medical Faculty, University of Leipzig,

Philipp-Rosenthal-Str. 55, 04103 Leipzig, Germany

Full list of author information is available at the end of the article

(c) The Author(s) 2021. Open Access This article is licensed under a Creative Commons Attribution 4.0 International License, which permits use, sharing, adaptation, distribution and reproduction in any medium or format, as long as you give appropriate credit to the original author(s) and the source, provide a link to the Creative Commons licence, and indicate if changes were made. The images or other third party material in this article are included in the article's Creative Commons licence, unless indicated otherwise in a credit line to the material. If material is not included in the article's Creative Commons licence and your intended use is not permitted by statutory regulation or exceeds the permitted use, you will need to obtain permission directly from the copyright holder. To view a copy of this licence, visit http://creativecommons.org/licenses/by/4.0/. The Creative Commons Public Domain Dedication waiver (http://creativeco mmons.org/publicdomain/zero/1.0/) applies to the data made available in this article, unless otherwise stated in a credit line to the data. 
Conclusion: GPs in Germany have frequent contact with osteopathy, and the vast majority have recommended osteopathic treatment to some extent in their practice, with foci and opinions comparable to other Western countries. The discrepancy between GPs making frequent referrals for osteopathic treatment while self-assessing to have little knowledge about it demonstrates need for intensified research on the collaboration with osteopaths and how to best integrate osteopathic treatments. Our results may help to focus future effectiveness studies on most relevant clinical conditions in general practice.

Keywords: Osteopathic medicine, General practice, Osteopathic manipulative treatment, Complementary alternative medicine

\section{Background}

Osteopathy, also referred to as osteopathic medicine or osteopathic manipulative treatment (OMT), is a complementary medicine with its own philosophy, methods of diagnosis and manual therapy [1]. Focus is placed on the human body unity, determined by autoregulation and the interactions of anatomy and physiological function. The treatment method was founded by US-American physician and preacher Andrew Taylor Still in the late nineteenth century and spread from there to Europe and many other parts of the world [2].

The regulation of osteopaths is diverse among European countries. While in Denmark, Finland, France, Iceland, Lichtenstein, Malta, Portugal, Switzerland and the UK osteopathy is approved and regulated by the state [35], in Germany there is no legally protected professional title and no uniform training or curriculum exists. Nevertheless, with around 10,000 osteopaths and more than 10 million patient contacts per year, osteopathy is an recognizable economic and financial part of the health sector in Germany [6]. Osteopathy in Germany legally has been defined as a medicine system that can only be applied legally by physicians or state-approved alternative practitioners ("Heilpraktiker"). However, osteopathy is not accredited as official additional training for physicians in Germany. Physiotherapists may only treat patients with osteopathic techniques when prescribed by a physician, although they cover a large part of the osteopathic treatment [7]. Osteopathic training in Germany mostly takes place at private schools or universities that are partially and voluntarily supervised through associations of osteopaths or alternative practitioners. The curricula and the extent of training hours show a high variation among schools [1].

Evidence for the effectiveness of osteopathic treatment is scarce for most indications not directly related to musculoskeletal problems of the spine (e.g., low backpain) and often has methodological problems [1, 8].

Many German health insurance organisations reimburse the costs for osteopathic treatment partially, if a physician recommends this kind of treatment [9]. General practitioners (GPs) are often the first professional contact for patients seeking osteopathic treatments. That's why patients enquire them with questions towards the indications, effectiveness and safety. However, little data and knowledge of the relationship and views of German GPs on osteopathy is available.

The present study explored the knowledge, beliefs and attitudes among German GPs towards osteopathy, as well as their experience with osteopathy in practice. The study also aimed to identify associations between sociodemographic, job-related and experience-based variables which could influence the treatment recommendation for osteopathy. In addition, reasons for referral and expectations of benefit for selected patient groups and treatment occasions were investigated.

\section{Methods \\ Sampling and design}

A cross-sectional survey of a random sample of 1000 GPs across Germany was performed. The sample size was calculated based on a number of 45,467 GPs working in Germany in 2019 [10], aiming for a level of confidence of $95 \%$ and a precision of $5 \%$. Due to the controversial topic, we assumed a response rate lower than average of 30 to $40 \%$ [11]. So, we decided to contact 1000 GPs by mail. Numbers of selected GPs for each federal state were balanced to the number of respective practicing GPs based on 2018 figures of the Associations of Statutory Health Insurance Physicians (Kassenärztliche Vereinigungen) [12, 13]. From 200 randomly chosen postal codes, five GPs having their practice in the respective area were selected by random draw from publicly available registers. If there were fewer than five GPs registered, the missing addresses were taken from another random postal code of the same state.

In February 2019, selected GPs were mailed the questionnaire, as well as a formal cover letter containing information about the study and a privacy statement. After 2 months, a reminder was sent. No incentives were offered. The survey was closed for evaluation in July 2019. Participation in the study was voluntary, and completed questionnaires were returned by fax or mail. The detailed sampling process is shown in Fig. 1. 


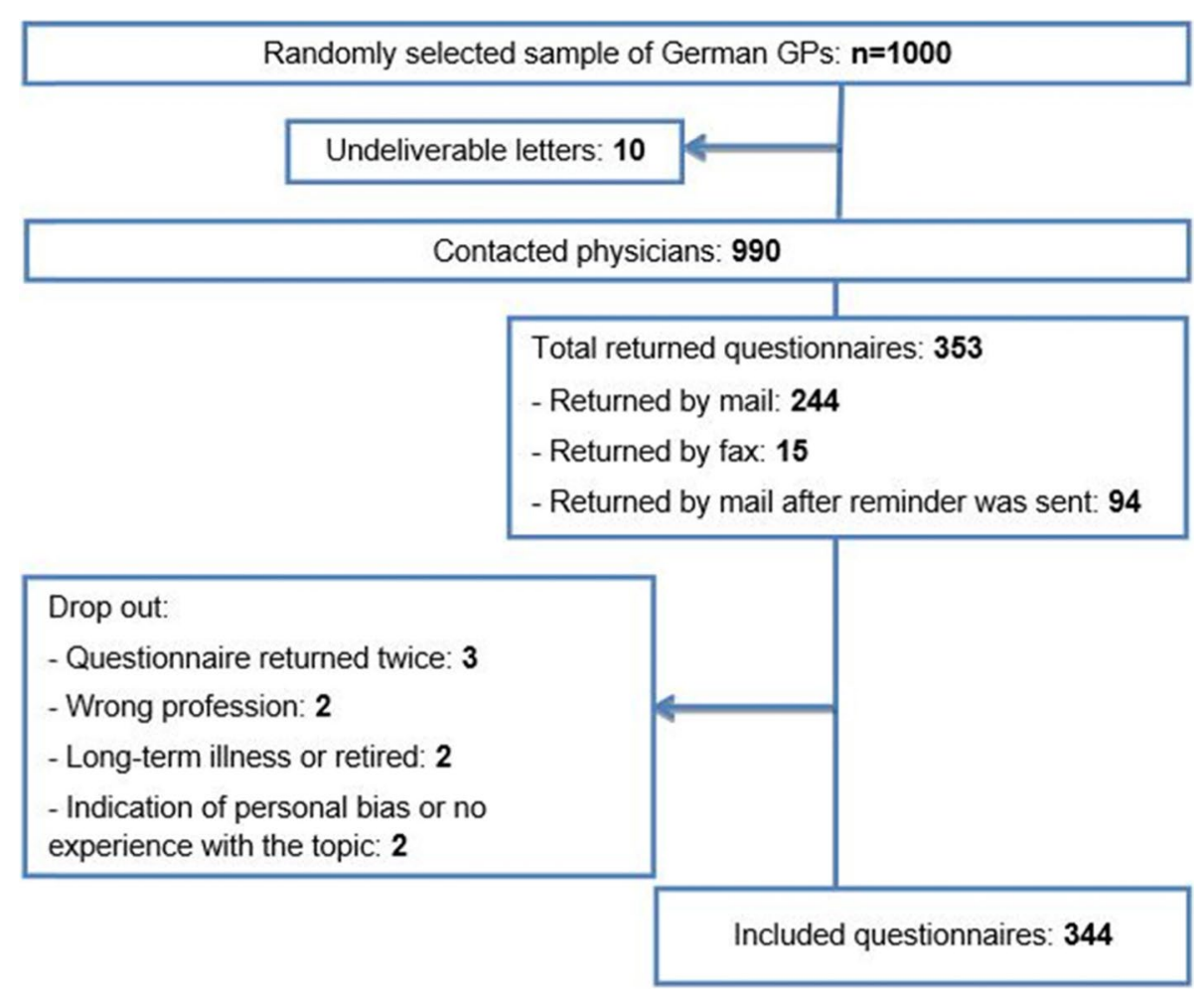

Fig. 1 Sampling flow chart

\section{Questionnaire}

The questionnaire was self-designed with the input and expertise of an interdisciplinary research team consisting of experienced GPs and physicians (one with additional expertise in osteopathy), a social scientist and a medical student. An unsystematic literature search using the keyword "osteopathic treatment" was performed in Medline/ Pubmed and the Cochrane Library considering the number of publications found for the most common presenting complaints. Positive or negative effect ratings were not considered. This search identified 15 common conditions, that were most frequently addressed in the identified studies. Those conditions should be rated by the participants regarding expected benefit of osteopathic treatment. To ensure comprehensibility and face validity, the questionnaire was pre-tested by $8 \mathrm{GPs}$, including subsequent feedback discussions. After minor modifications, the final version contained 55 items and could be completed in 5 to $10 \mathrm{~min}$. An English translation of the questionnaire is provided in Additional file 1.

\section{Data collection and statistical analyses}

Returned questionnaires were scanned and read out using the software Form Pro 3.0 (OCR Systems, Germany). Collected data was cleaned, and the free text answers were added manually. Statistical analyses were performed using
IBM SPSS Statistics 24 for Windows. Frequencies were presented as $\%_{\text {valid }}\left(\mathrm{n}_{\text {absolute }} / \mathrm{n}_{\text {valid }}\right)$, continuous variables as mean \pm standard deviation (SD). We categorized the open text diagnoses into subcategories with different levels of specification, depending on related clinical pictures. The outcome variable and key question "Have you ever recommended treatment by an osteopath to a patient?" was coded binary $(0=$ in a few cases/no, never; $1=$ yes, regularly/occasionally). The response options were subjective without numerical specifications for the frequency of recommendation. Univariable and multivariable binary logistic regression was used as the primary analysis to estimate predictive factors of recommendation behavior (dependent variable) including 95\% confidence intervals (95\% CI). After selecting variables based on content to include in the analysis, individual tests of the items to exclude multicollinearity were undertaken. Reasons for exclusion were correlation of two variables $r>0.6$, variable categories with a total of $n<10$ respondents, generally high rate of missing answers for single questions $(n<300)$ and $p>0.5$ in the following Chi-square tests. Covariates gender (men vs. women), age (<40 vs. $\geq 40)$, personal treatment experience (yes vs. no) and knowledge (very good/good vs. little/ no) were investigated as independent predictor variables. In an exploratory approach, backward LR/stepwise and forward LR/stepwise sensitivity analyses were performed. 
To estimate the general attitude and the subjective appraisal towards osteopathy, we used five questions of the questionnaire and created a score to summarize this general view of GPs. For each question, a value between 0 (rather skeptical) and 3 (rather open-minded) was assigned to generate a total score. A higher score represents a more positive attitude towards osteopathy. Linear regression (stepwise) explored the relationship between this score and selected predictor variables as above.

\section{Results}

\section{Descriptive analysis}

Response

The response rate was $34.4 \%$, with 344 (of 1000) analyzable data sets. Figure 1 shows a flow chart with details about returned questionnaires and reasons for exclusion. Response rate was heterogeneous, with the highest rates in the federal states Saxony, SchleswigHolstein and Thuringia (44.6 to 50.0\%) and lowest rates in Hessen (24.6\%) and North Rhine Westphalia (26.2\%).

\section{Sociodemographics and job-related characteristics}

Of the respondents, $46.5 \%$ were women. The mean age was $54 \pm 9.5$ years (Median 56.0, range $30-80$ ). $64.5 \%$ of the GPs had at least one additional qualification, while only 4 out of 344 (1.2\%) had extensive training in osteopathy. Table 1 shows a summary of sociodemographics and comparable data of all German GPs, available from publicly accessible registers [14].

Table 1 Sociodemographic and job-related factors - total sample compared to all German GPs in \%

\begin{tabular}{|c|c|c|}
\hline Variable & All participating GPs in \% ( $n / n v a l i d)$ & $\begin{array}{l}\text { All } \\
\text { German } \\
\text { GPs in \% }\end{array}$ \\
\hline Female & $46.5(160 / 344)$ & 45.9 \\
\hline Age in years (mean $\pm S D$ ) & $54.8 \pm 9.5$, Median: 56.0 & 55.5 \\
\hline$\leq 39$ years old & $6.8(23 / 340)$ & 6.3 \\
\hline $40-49 y$ & $20.6(70 / 340)$ & 20.4 \\
\hline $50-59 y$ & $39.7(135 / 340)$ & 37.2 \\
\hline $60-65 y$ & $19.4(66 / 340)$ & 20.1 \\
\hline$>65 y$ & $13.5(46 / 340)$ & 15.9 \\
\hline Has a doctor's degree or habilitation & $64.3(205 / 319)$ & \\
\hline Training in Osteopathy & $1.2(4 / 344)$ & \\
\hline Completed at least one additional qualification & $64.5(222 / 344)$ & a \\
\hline Manual medicine/Chiropractic/Physical medicine & $19.5(67 / 344)$ & 8.4 \\
\hline Emergency medicine & $13.7(47 / 344)$ & 8.1 \\
\hline Acupuncture & $12.8(44 / 344)$ & 7.3 \\
\hline Psychotherapy/Psychosomatics & $9.0(31 / 344)$ & 7.4 \\
\hline Homeopathy & $8.7(30 / 344)$ & 3.0 \\
\hline Sports medicine & $8,4(29 / 344)$ & 6.1 \\
\hline Working in own practice (versus employed) & $85.7(288 / 336)$ & 79.7 \\
\hline Years having own practice (mean \pm SD, nvalid $=286$ ) & $20 \pm 10.6$ & \\
\hline \multicolumn{3}{|l|}{ Legal structure of the practice } \\
\hline Single practice & $58.5(158 / 270)$ & 55.7 \\
\hline Joint practice & $37.8(102 / 270)$ & 39.0 \\
\hline Medical care center ("MVZ") & $3.7(10 / 270)$ & 5.3 \\
\hline \multicolumn{3}{|l|}{ Practice environment (self-assessment) } \\
\hline Big city & $22.1(73 / 330)$ & \\
\hline Small city & $37.6(124 / 330)$ & \\
\hline Countryside & $40.3(133 / 330)$ & \\
\hline \multicolumn{3}{|l|}{ State where doctor is working } \\
\hline States of former East Germany + Berlin & $24.5(68+16 / 343)$ & 20.8 \\
\hline States of former West Germany & $75.5(259 / 343)$ & 79.2 \\
\hline
\end{tabular}

${ }^{a}$ Percentage refers to all physicians in outpatient settings, not only GPs (data not separately available) 


\section{Handling of osteopathy in daily practice}

Of all respondent GPs, 33.7\% reported recommending osteopathy frequently, $35.8 \%$ occasionally, $18.5 \%$ in a few cases and $12.0 \%$ never. Nevertheless, almost every GP $(91.3 \%)$ had already given a written recommendation or referral for osteopathic treatment to patients. In most cases, this recommendation happened partly on their own suggestion and partly following the patient's request (64.6\%). In $29.9 \%$ of cases, the referral occurred on the patient's request only, and in $5.4 \%$ of cases, on the physicians' suggestion alone. If the physicians reported rejecting making a formal recommendation for patients $(9.3 \%)$, the major reasons were lack of trust/evidence (40.0\%) and that they considered other therapies to be better or more effective (24.0\%).

The majority of GPs surveyed (77.6\%) personally knew an osteopath working in the catchment area of their practice, and of these GPs, $57.1 \%$ had collaborated with them. The questions addressing cooperation quality revealed that $42.9 \%$ of GPs exchanged medical findings with their local osteopath. The majority of GPs considered the information exchanged comprehensible $(74.2 \%)$ and useful for treatment (64.9\%). Willingness to cooperate with osteopaths was present in two-thirds $(67.8 \%)$ of the doctors. More than one-third of GPs (39.4\%) received patients sent by an osteopath. Furthermore, $33.7 \%$ of all GPs had been treated by an osteopath themselves. Almost two-thirds (66.1\%) knew a qualified osteopath whom they would recommend to patients.

When asked about the general feedback given by patients after osteopathic treatment, $69.0 \%$ of doctors reported receiving overall positive feedback. $22.7 \%$ of respondents indicated they received heterogeneous feedback, and only $2.7 \%$ emphasized that they received negative feedback. $5.7 \%$ of GPs indicated they did not receive patient feedback after osteopathic treatment.

\section{Knowledge}

Reported subjective responses on knowledge were widely divergent, from self-perceived very wellinformed $(7.6 \%)$ and good knowledge $(34.6 \%)$ to little $(52.6 \%)$ and almost no expertise (4.4\%) in osteopathy. From $n=628$ submitted replies (multiple answers were possible), personal narratives (38.1\%) and medical journals $(28.2 \%)$ were the highest rated sources of information. Internet (7.8\%), non-medical journals (5.1\%), training/further education or congresses (4.1\%) and exchange with colleagues or patients $(2.9 \%)$ followed. Additionally, $17.7 \%$ of GPs stated that they have little or no information on the subject of osteopathy at all.
Nearly three-quarters (72.2\%) of GPs were aware of which medical professions are allowed to practice osteopathy in Germany.

\section{Treatment occasions and patient spectrum}

When asked for the most frequent reason for recommendation of osteopathy, in total 629 reasons for encounter were mentioned and clustered into nine categories. The most frequent reasons listed were back pain and complaints concerning the spinal column (cervical/thoracic/ lumbar spine, sacroiliac joint, discus prolapse). Other treatment occasions that could not be assigned to any of the selected categories $(n=20$; e.g., dysmenorrhea, scar pain, post-traumatic or postoperative treatment, insomnia, heart complaints) are not mentioned in the detailed percentages (Fig. 2).

Asked about the treatment occasions for which GPs prefer to refer patients to osteopaths, physicians rated musculoskeletal causes the highest, in line with the open-text answers. Complaints associated with the inner organs were faced with lower expectations (Fig. 3). Middle-aged and chronically ill patients were attributed the biggest benefit for OMT (Fig. 4). Female GPs had a significantly higher expectation of benefit assessment than male GPs in 9 of 15 clinical pictures and 4 of 7 patient groups.

\section{Opinions on scientific and political issues of osteopathy}

GPs were asked about five current issues of debate concerning osteopathy in respect to the evidence base, need for information, reimbursement by health insurance companies, limitation of indications and establishment of a distinct health profession (Fig. 5).

\section{Opinion score}

With $n=321$ GP included, we have scored the "opinion score" by five questionnaire items with a standard distributed outcome (mean value 8.3 points \pm 3.5 , range $0-15$ ). This serves as an attempt to represent approval and rejection of the treatment method osteopathy. No multicollinearity $(>0.7)$ could be detected between the five questions.

When correlating the items already examined in the cross table with the opinion score, a clear association with gender $(p=0.004)$, knowledge, patient feedback, self-treatment, and knowing a locally based and qualified osteopath (all $p<0.001$ ) for a higher opinion score was shown. Correlation to age, additional qualification and the federal state could not be found.

Notably, multivariate regression showed higher attitude score in physicians with former self-treatment ( $p<0.001$; regression coefficient 2.78, 95\%CI 1.97-3.57). GPs, who have already been treated themselves, are more 


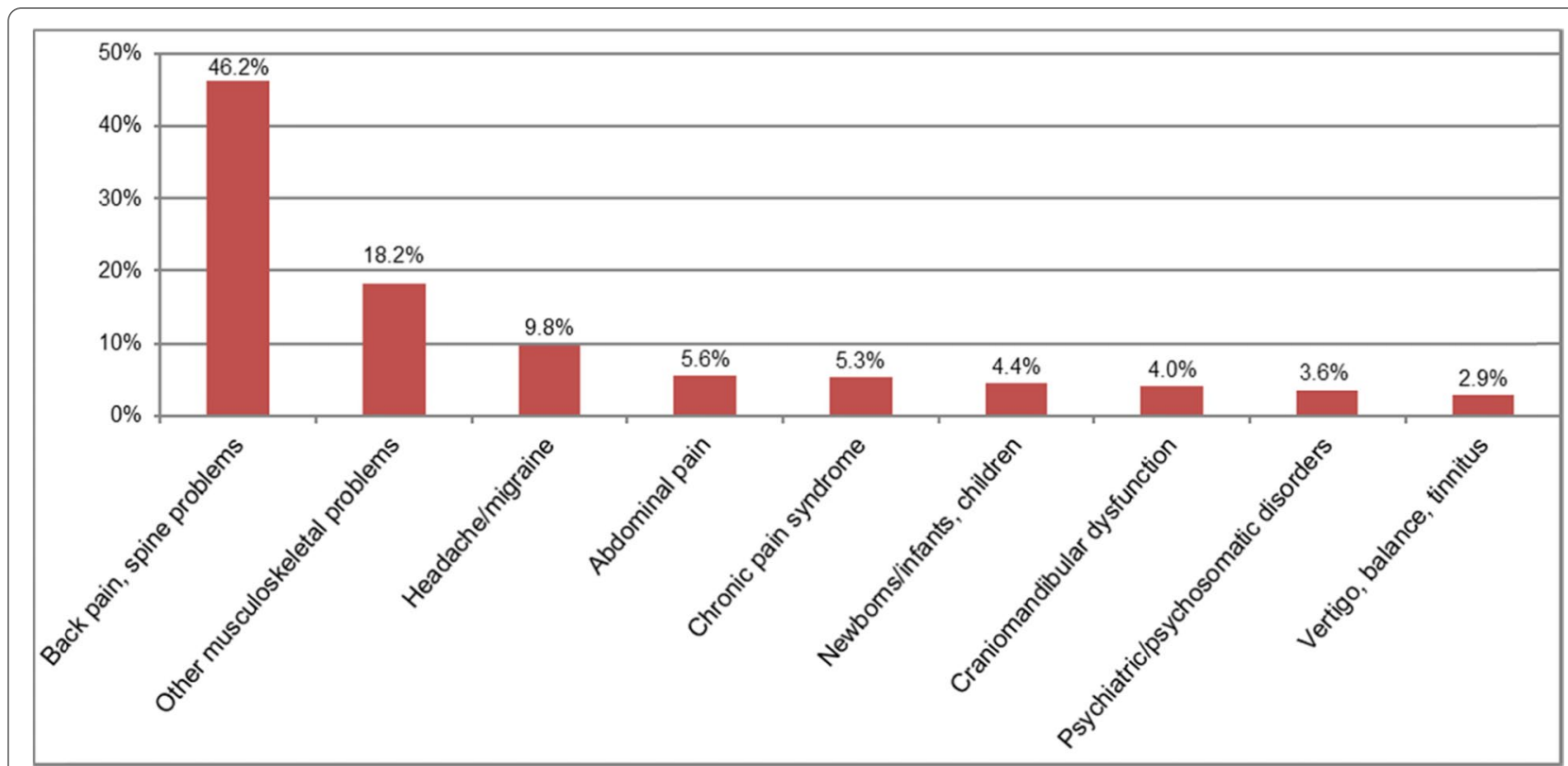

Fig. 2 Open text reasons for encounter of most likely recommended clinical pictures for osteopathic treatment in \% $(n=450)$

open-minded towards osteopathy. State and gender also remained as influencing variables.

\section{Associations with treatment recommendations}

Results of bivariate associations are presented as absolute and relative numbers from the selected items in Additional file 2. Female practitioners (OR 2.09; 95\%CI 1.29-3.38) more frequently recommended osteopathic treatment. GPs who know a local (OR 4.11; 95\%CI 2.436.96) and qualified (OR 6.94; 95\%CI 4.14-11.64) osteopath recommended OMT more often, as well as GPs who have been treated themselves (OR 5.14; 95\%CI 2.729.72). Furthermore, more frequent treatment recommendation was positively associated with good feedback from patients (OR 7.26; 95\%CI 4.31-12.22) and knowledge of the GP about osteopathy (OR 1.91; 95\%CI 1.17-3.10). No significant association could be found with age, additional qualification, or catchment area and structure of the practice.

Four covariates were preselected for multivariate analyses and analyzed on the basis of 302 questionnaires (87.8\% of all GPs) with complete answers. Multivariable analysis predicting self-assessed occasionally or regularly (vs. few cases or no, never) recommendation of osteopathy revealed positive associations for physicians with own treatment experience (88.3\% vs. 59.5\%; OR 5.44; $95 \%$ CI 2.77-10.70). Furthermore, female physicians seem to prefer osteopathic treatment $(77.7 \%$ vs. $62.5 \%$; OR 1.62 ; 95\% CI 0.94-2.82). These results were confirmed in the sensitivity analysis.

\section{Responder and non-responder analyses}

No difference was stated between response and gender ( $p=0.229)$, GPs practicing in former Eastern or Western Germany $(p=0.094)$ and academic degree of GPs (see Table 1).

Non-response rate among female and male GPs was 63.8 and 67.0\%, respectively. Considering GPs in former Eastern and Western Germany, this rate was 56.9 and $67.8 \%$. There was no difference in the frequency of academic degree for responders (64.3\%) and non-responders $(64.0 \%)$.

\section{Discussion}

Osteopathy seems to be a well-known topic for German GPs, as nearly all respondents had already given written recommendation for an osteopathic treatment to their patients. More than three-quarters of all respondents knew an osteopath near their practice, two-thirds could imagine cooperation with osteopaths, almost two-thirds could name an osteopath they would send patients to and more than half of the GPs already exchanged information with an osteopath about patients treated together. Similar rates of treatment recommendations were also given in other publications [15-21]. A study among GPs in London found that osteopathy was the most common referral among treatments categorized as Complementary Alternative Medicine (CAM). 84\% of these physicians had received requests from patients for a referral, and $78 \%$ had already suggested a referral for osteopathy [18]. Among British GPs, 9.1\% referred and 31\% endorsed 


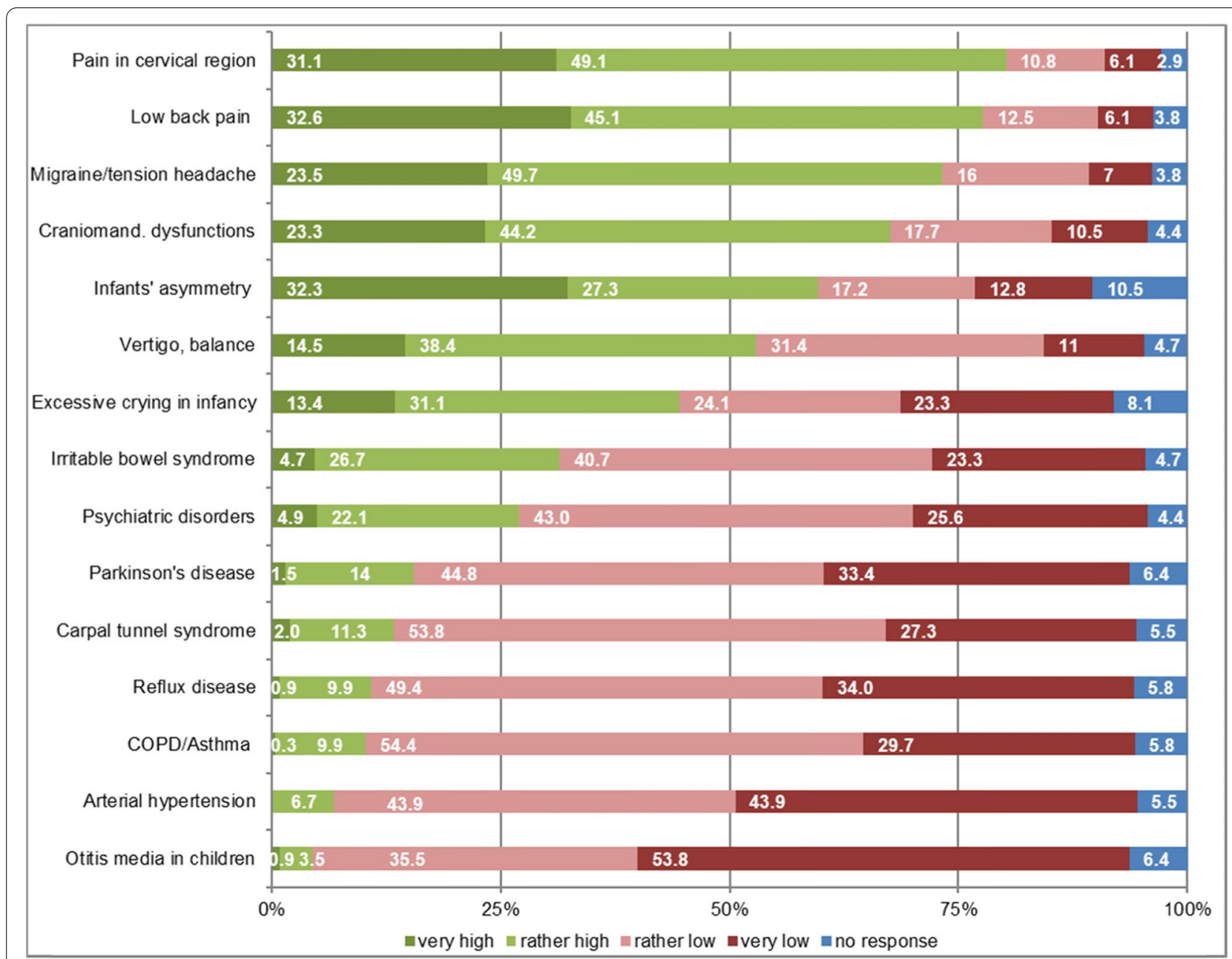

Fig. 3 Expectations of benefit from osteopathic treatment for different pre-selected reasons for encounter via GPs self-assessment in \% $(n=344)$

OMT within the last week [15]. In an Australian survey, $63 \%$ of GPs referred patients to osteopaths and chiropractors at least a few times per year [21]. A further Australian study from 2005 showed a lower recommendation rate for osteopathy of $23 \%$ within the last 12 months [20]. Active physicians' recommendation for CAM plays a significant role in the patient's appropriate use, perception and evaluation of the therapy [22,23]; therefore, the GP has a significant influence on the patient's decision making. When comparing our data with studies from other western countries, it is important to note that the historical development of osteopathy has taken place at different speeds and depths. Additionally, the allocation of osteopathy to the respective national health system is multifaceted.

Despite the regular and diverse points of contact, more than half of the physicians surveyed have little or no knowledge about osteopathy itself. Personal narratives were cited by $69.5 \%$ as one source of information, and more than one-quarter did not know which persons are legally justified to apply osteopathic treatments. Those facts reveal a remarkable lack of information among German GPs. Comparable percentages were given in the UK, with $60 \%$ of GPs defining themselves as having little confidence in their osteopathic knowledge [15]. Other studies from the Australia and Canada showed similar numbers [19, 24]. However, it seems that British GPs were significantly better informed about official qualifications of osteopathic practitioners than hospital doctors, and $84 \%$ of these GPs at least knew the main principles of osteopathy [18].

Diagnoses concerning the spine and other musculoskeletal locations made up more than $60 \%$ of the free text diagnoses. In the expectations of benefit given by GPs, low back pain, cervical/neck complaints and headache/ migraine were named most frequently. This is in line with the comparatively high amount of external evidence on osteopathic manipulative treatment for (lower) back pain 


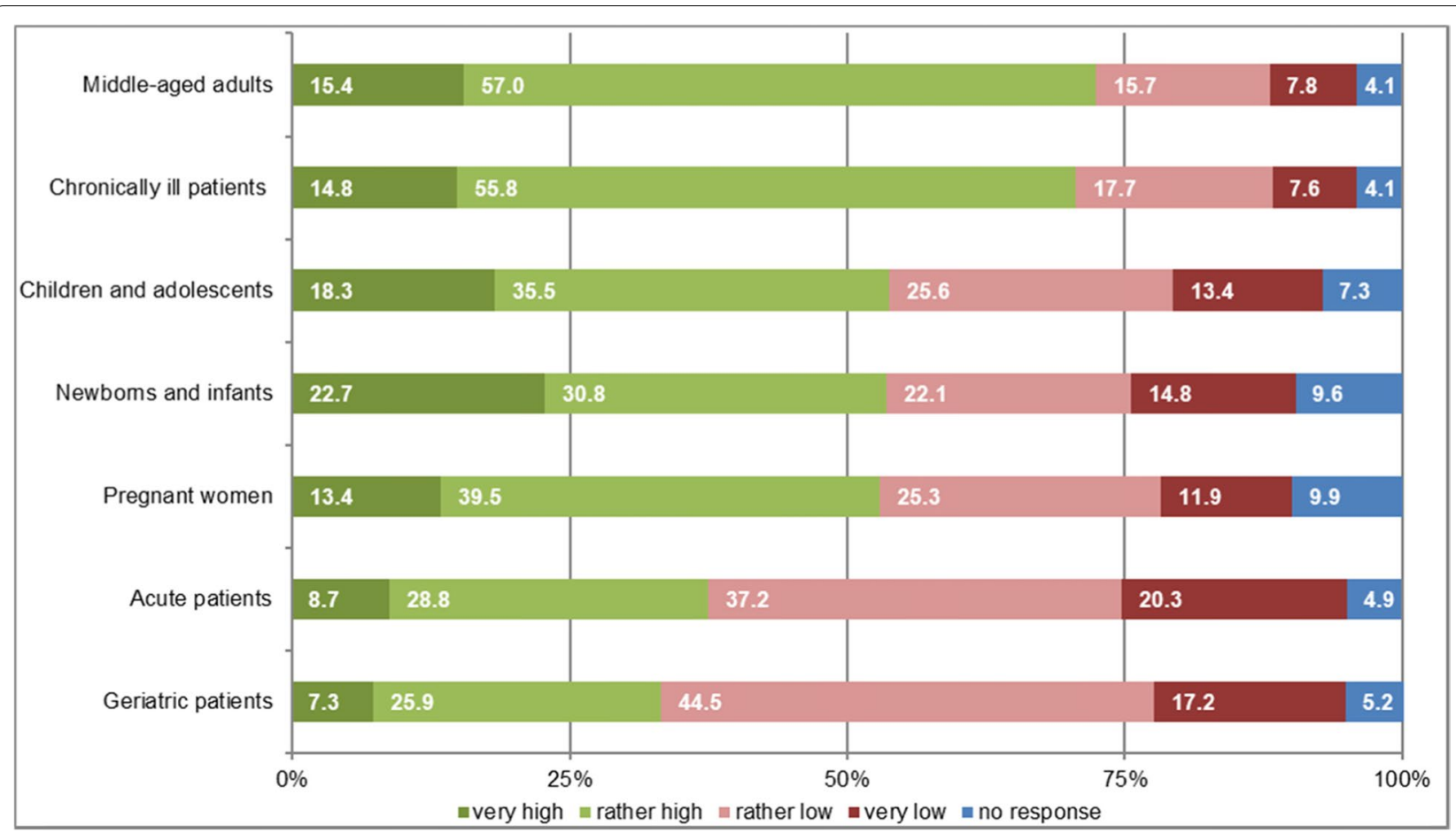

Fig. 4 Expectations of benefit from osteopathic treatment for different patient groups via GPs self-assessment in \% $(n=344)$

There is no evidence for the effectiveness of osteopathy.

The range of indications for osteopathy should be clearly limited.

For specialists in general medicine, a more detailed knowledge of osteopathy is useful.

I consider the (partial) coverage of costs for osteopathic treatments by the statutory health insurance companies to be justified.

The occupation "osteopath" should be established as an independent health profession in Germany.

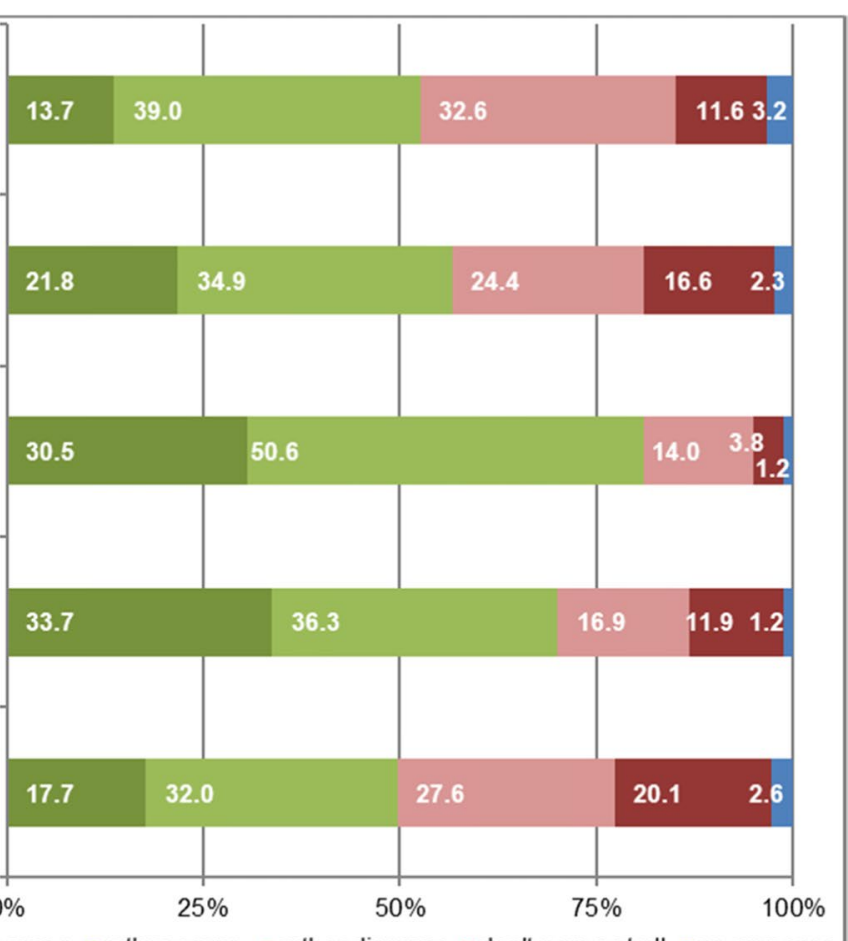

m totally agree $=$ rather agree $=$ rather disagree $=$ don't agree at all $\mathbf{m}$ no response

Fig. 5 "How do you agree with the following statements?" answers in \% from all GPs ( $n=344)$ 
[25-28]. In addition, our findings are also in line with the most common specific complaints evaluated in Benelux Osteosurvey 2013 with osteopathically self-evaluated treatment occasions [4]. They were mostly focused on musculoskeletal and spinal column-related conditions. For $81 \%$ of patients in the Swiss Osteosurvey 2018, musculoskeletal pain mainly located in the cervical, lumbar and fascial area played a role in the decision towards OMT [29]. Meta-analyses of a Spanish osteopathic patient profile showed lumbar and cervical diagnoses as well as headaches as the main reasons for a consultation [30]. Infants' asymmetry played a minor role. Some special groups of patients (e.g., children, pregnant women), which are often described in effectiveness studies of OMT [31, 32] as well as clinical conditions (e.g., infant asymmetry or excessive crying) are rather seldom present in German GP practices and mostly treated by specialists. This might be a reason for the low numbers of recommendations for those patients in this study.

Women in the current study are more likely to be convinced about osteopathy across almost all items of the questionnaire and give a better benefit rating. This is in line with the German government's health report on CAM from 2002 which noted that women are more open to the use of unconventional treatment methods in general [33]. Women use alternative treatment methods significantly more often than men [34,35]. This finding is therefore not specific for our study and osteopathy but rather generally valid for women and CAM.

If the physician knows an osteopath who is qualified and, at best, lives nearby, if the patients' feedback is positive and if the GP has even been treated himself/herself, the recommendation rate of therapy to patients is significantly higher. This association was also found in other studies [36-38] and is in line with results from a study performed among Estonian GPs in 2007. GPs who have been treated themselves and who have greater belief in the effectiveness and evidence base for osteopathy more often refer to osteopaths [39]. In the UK study, the lowest $10 \%$ scores for estimated effectiveness of osteopathy were given by GPs who were male, over 50 years old, and/ or working in a single practice [15]. In contrast, an Australian survey from 2013 showed significant associations for osteopathic referral with knowledge about osteopathy, patient load per week, own experience with CAM, patients asking and request for referral, positive feedback from patients and belief in the efficacy of osteopathy. Demographic factors like age, gender, level of rurality and location of medical school were not predictive for referral to osteopaths [24]. Contrary to our findings, there was no significant difference found between female and male GPs referring chiropractic/osteopathic treatment in an US-American study [16].
Our questionnaire contained five items on GPs' opinions and views towards osteopathy. Approximately a balanced number of positive and negative opinions among GPs was observed regarding establishing an independent osteopathic profession, an overall lack of sufficient evidence for osteopathy and a demand to limit osteopathic treatment indications. Three-quarters favored having costs covered by health insurances and supported more knowledge about osteopathy for GPs. Thus, the topic seems to polarize. Critical opinions are partly in contrast to the widespread practical use of osteopathy. The opinions in other western countries diverge widely. OMT was rated in comparable international surveys as useful and effective among 34 to $50 \%$ of GPs [15, 21, 24]. In contrary, $50 \%$ of Australian GPs assessed osteopathic education as not primarily evidence based [19]. Osteopathy as part of the health care system would be accepted by $45.2 \%$ of GPs in Estonia [39]. In the UK, 52\% of GPs indicated that the NHS should pay for this therapy [15]. Moreover, $91 \%$ of GPs agreed all osteopathic practitioners should be formally qualified and licensed by law [18]. The questions of evidence, political recognition and regulation of indications for OMT remain to be clarified in Germany.

\section{Strengths and limitations}

Regarding the link between GPs and osteopaths, our cross-sectional study is to our knowledge the first of its kind in Germany. The sample is balanced throughout the whole country with a reasonable sample size, and the substantial response rate supports the explanatory power of our findings.

We cannot exclude or definitively determine the size of a selection bias due to interest in the topic and a positive view towards CAM and osteopathy. Social desirability might also have influenced response rates.

In the questionnaire, free text diagnoses and unspecific answers complicated a precise categorization of some diagnoses.

To gauge general attitudes towards osteopathy, we used a set of five items rather than a single direct question. We asked indirectly and included several dimensions of opinion. The proposed score is based on self-designed items and has not been validated. A direct question like "How much do you sympathize with osteopathy in general?" may have been helpful. Furthermore, we figured out the problem of causal relationship and the complete exclusion of multicollinearity as difficult to solve. We could not distinguish whether a GP was first self-treated and then recommended OMT to patients, or vice versa. 


\section{Conclusion and implications for practice}

Osteopathy is frequently recommended in general practices in Germany, more often among female GPs and physicians having their own previous experience with osteopathy. Most frequent reasons for a recommendation are disorders of the spinal column followed by other complaints of the musculoskeletal system and headaches. This study can provide the basis and orientation for future research on patients' needs and efficacy of osteopathic treatment. Nevertheless, there is a lack of information among German GPs. Targeted, concise information material or guidelines [2] about the philosophy, treatment methods, risks, scientifically evidence base and the legal situation could support GPs in their function as health-care adviser dealing with osteopathy and may lead to the safe and well-informed use of this treatment for patients.

\section{Abbreviations}

CAM: Complementary Alternative Medicine; CMD: Craniomandibular Dysfunction; COPD: Chronic obstructive pulmonary disease; GP: General practitioner; OMT: Osteopathic manipulative treatment.

\section{Supplementary Information}

The online version contains supplementary material available at https://doi. org/10.1186/s12875-021-01545-2.

Additional file 1. English translation of the questionnaire (original language: German).

Additional file 2. Cross table with univariate predictors of recommendations (all items matched, ntotal $=341$ ).

\section{Acknowledgements}

The authors want to thank all participating GPs for taking the time to contribute to this study despite their demanding work. In addition, we would like to express our sincere thanks for the organizational, content-related and emotional support provided by the staff of the Department of General Medicine, especially the other student assistants and the secretary's office represented by Mrs. Britt Häusler and Mrs. Nicole Schäfer.

\section{Authors' contributions}

JK contributed to design of the study, data compilation and questionnaire development; collected all data; performed data analysis and interpretation; and contributed to drafting the manuscript. GLS contributed to the conception, idea and design of the study; design and pretesting of the questionnaire; evaluation and presentation of the data; drafting of the manuscript; and supported content development and organization throughout the entire project. TD contributed to creating and pre-testing the questionnaire; gave advice on statistical analysis and interpretation of the data, descriptive illustration, logistic regression; and helped with drafting and formatting the manuscript. AKG and MB contributed content-related advice on the logic and context of the manuscript. SU contributed to statistical analysis and interpretation of data, especially logistic regression. TF initiated the study with the idea for the research topic, provided content-related input, and reviewed and revised the manuscript. All authors read and approved the final manuscript.

\section{Funding}

There was no external funding for this study.

\section{Availability of data and materials}

The datasets used and analyzed during the current study are available from the corresponding author on reasonable request. Open Access funding enabled and organized by Projekt DEAL.

\section{Declarations}

\section{Ethics approval and consent to participate}

According to the Model Professional Code for Physicians [40], an explicit ethics approval was deemed unnecessary for this study because the questionnaires were anonymous and no personal identifiable data was collected. The participating GPs were informed by a written formal cover letter about the use and publication of their anonymized data for this study. Participation in the study was completely voluntary. Returning the completed questionnaire was interpreted as informed consent to participate in the study.

The Ethics Committee at the Medical Faculty of the University of Leipzig confirmed in their "waiver" on 21st of April 2021 that there is no professional legal and ethical consulting obligation for this project through the anonymization of the questionnaire participants.

All procedures performed in studies involving human participants were in accordance with the ethical standards of the institutional and / or national research committee and with the 1964 Helsinki declaration and its later amendments or comparable ethical standards.

\section{Consent for publication}

Not applicable, as the manuscript does not contain data from any individual person.

\section{Competing interests}

The authors declare that they have no competing interests.

\section{Author details}

${ }^{1}$ Department of General Practice, Medical Faculty, University of Leipzig, Philipp-Rosenthal-Str. 55, 04103 Leipzig, Germany. ${ }^{2}$ Institute of General Practice and Family Medicine, Martin-Luther-University Halle-Wittenberg, Magdeburger Str. 8, 06112 Halle (Saale), Germany.

Received: 15 April 2021 Accepted: 17 September 2021

Published online: 07 October 2021

\section{References}

1. Osteopathic International Alliance. Osteopathic healthcare - global review of osteopathic medicine and osteopathy. 2020. https://oiall iance.org/wp-content/uploads/2021/02/OIA_Report_2020_FINAL.pdf. Accessed 20 Aug 2021.

2. World Health Organization. Benchmarks for training in osteopathy. 2007. https://www.who.int/medicines/areas/traditional/BenchmarksforTrainin ginOsteopathy.pdf. Accessed 2 Apr 2021.

3. Steel A, Blaich R, Sundberg T, Adams J. The role of osteopathy in clinical care: broadening the evidence-base. Int J Osteopath Med. 2017;24:32-6.

4. van Dun PL, Nicolaie MA, van Messem A. State of affairs of osteopathy in the Benelux: Benelux Osteosurvey 2013. Int J Osteopath Med. 2016;20:3-17.

5. European federation and forum for osteopathy EFFO. Regulation of Osteopathy in Europe. https://www.effo.eu/regulation-in-europe/. Accessed 20 Aug 2021.

6. Bundesverband Osteopathie e.V. (BVO). BVO-Patientenumfrage 2018 Wirkung und Akzeptanz der Osteopathie. 2018. https://bv-osteopathie. de/wp-content/uploads/2020/02/BVO-Patienten-Umfrage-2018.pdf. Accessed 2 Apr 2021.

7. Newiger C. Die Ausübung der Osteopathie: Vor- und Nachteile eines nicht existenten Berufs. 2016. https://hpo-osteopathie.de/up/datei/co. med_newiger_1606_ow.pdf. Accessed 2 Apr 2021.

8. Wissenschaftlicher Beirat Bundesärztekammer, Haas N, Hoppe J-D, Scriba P. Wissenschaftliche Bewertung osteopathischer Verfahren. 2009. https:// www.aerzteblatt.de/pdf.asp?id=66809. Accessed 2 Apr 2021.

9. Ismail-Tsaous E. Bezuschussung osteopathischer Behandlungen: Versicherte und Krankenkassen profitieren. Osteopathische Medizin. 2014;15:26-8. 
10. Statista. Anzahl der Hausärzte in Deutschland bis 2020: Statista; 2020. https://de.statista.com/statistik/daten/studie/191814/umfrage/anzahlder-hausaerzte-in-deutschland/. Accessed 2 Apr 2021

11. Creavin ST, Creavin AL, Mallen CD. Do GPs respond to postal questionnaire surveys? A comprehensive review of primary care literature. Fam Pract. 2011;28:461-7.

12. Bundesärztekammer. Ärztestatistik 2018. 2018.

13. Kassenärztliche Bundesvereinigung. Gesundheitsdaten - Regionale Verteilung der Ärzte in der vertragsärztlichen Versorgung. https://gesun dheitsdaten.kbv.de/cms/html/16402.php. Accessed 30 Aug 2021.

14. Munz, H. (KBV). Statistische Informationen aus dem Bundesarztregister. 2019. https://www.kbv.de/media/sp/2019_12_31_BAR_Statistik.pdf. Accessed 2 Apr 2021.

15. White AR, Resch K-L, Ernst E. Complementary medicine: use and attitudes among GPs. Fam Pract. 1997;14(4):302-6.

16. Stussman BJ, Nahin RR, Barnes PM, Ward BW. U.S. physician recommendations to their patients about the use of complementary health approaches. J Altern Complement Med. 2020;26:25-33.

17. Morin C, Desrosiers J, Gaboury I. When, why, and how osteopaths and physicians communicate: lessons learned from the results of a mixed methods study. Int J Osteopath Med. 2017;26:3-9.

18. Perkin MR, Pearcy RM, Fraser JS. A comparison of the attitudes shown by general practitioners, hospital doctors and medical students towards alternative medicine. J R Soc Med. 1994;87:523-5.

19. Engel RM, Beirman R, Grace S. An indication of current views of Australian general practitioners towards chiropractic and osteopathy: a crosssectional study. Chiropr Man Ther. 2016;24:37.

20. Cohen MM, Penman S, Pirotta M, Da Costa C. The integration of complementary therapies in Australian general practice: results of a national survey. J Altern Complement Med. 2005;11:995-1004.

21. Wardle JL, Sibbritt DW, Adams J. Referrals to chiropractors and osteopaths, a survey of general practitioners in rural and regional New South Wales, Australia. Chiropr Man Ther. 2013;21:5

22. Rosemann $T$, Wensing $M$, Rueter $G$, Szecsenyi J. Referrals from general practice to consultants in Germany: if the GP is the initiator, patients' experiences are more positive. BMC Health Serv Res. 2006;6:5.

23. Sharp D, Lorenc A, Morris R, Feder G, Little P, Hollinghurst S, et al. Complementary medicine use, views, and experiences: a national survey in England. BJGP Open. 2018;2:5-12.

24. Verhoef MJ, Sutherland LR. Alternative medicine and general practitioners. Opinions and behaviour. Can Fam Physician. 1995;41:1005-11.

25. Franke H, Franke J-D, Fryer G. Osteopathic manipulative treatment for nonspecific low back pain: a systematic review and meta-analysis. BMC Musculoskelet Disord. 2014;15:286:8-20. https://doi.org/10.1186/14712474-15-286. PMCID: PMC4159549. PMID: 25175885.

26. Licciardone JC, Brimhall AK, King LN. Osteopathic manipulative treatment for low back pain: a systematic review and meta-analysis of randomized controlled trials. BMC Musculoskelet Disord. 2005;6:43.

27. Licciardone JC, Kearns CM, Minotti DE. Outcomes of osteopathic manual treatment for chronic low back pain according to baseline pain severity: results from the OSTEOPATHIC trial. Man Ther. 2013;18(6):533-40.
28. Williams NH, Wilkinson C, Russell I, Edwards RT, Hibbs R, Linck P, et al. Randomized osteopathic manipulation study (ROMANS): pragmatic trial for spinal pain in primary care. Fam Pract. 2003;20:662-9.

29. Vaucher P, Macdonald R, Carnes D. Osteopathy in Switzerland - practice and contribution to healthcare 2016-2017; 2018.

30. Alvarez Bustins G, López Plaza P-V, Carvajal SR. Profile of osteopathic practice in Spain: results from a standardized data collection study. BMC Complement Altern Med. 2018;18:129.

31. Posadzki P, Lee MS, Ernst E. Osteopathic manipulative treatment for pediatric conditions: a systematic review. Pediatrics. 2013;132:141-51.

32. Hensel KL, Buchanan S, Brown SK, Rodriguez M, Des Cruser A. Pregnancy research on osteopathic manipulation optimizing treatment effects: the PROMOTE study. Am J Obstet Gynecol. 2015;212:717-23.

33. Marstedt G, Moebus S. Inanspruchnahme alternativer Methoden in der Medizin. 2002. https://www.gbe-bund.de/pdf/alternat.pdf. Accessed 2 Apr 2021.

34. Härtel U, Volger E. Inanspruchnahme und Akzeptanz klassischer Naturheilverfahren und alternativer Heilmethoden in Deutschland -- Ergebnisse einer repräsentativen Bevölkerungsstudie [Use and acceptance of classical natural and alternative medicine in Germany--findings of a representative population-based survey]. Forsch Komplementarmed Klass Naturheilkd. 2004;11:327-34.

35. Kemppainen LM, Kemppainen TT, Reippainen JA, Salmenniemi ST, Vuolanto PH. Use of complementary and alternative medicine in Europe: health-related and sociodemographic determinants. Scand J Public Health. 2018;46:448-55.

36. Kier A, George M, McCarthy PW. Survey based investigation into general practitioner referral patterns for spinal manipulative therapy. Chiropr Man Ther. 2013:21:16.

37. Schmidt K, Jacobs PA, Barton A. Cross-cultural differences in GPs'attitudes towards complementary and alternative medicine: a survey comparing regions of the UK and Germany. Complement Ther Med. 2002;10:141-7.

38. Forrest CB, Nutting PA, von Schrader S, Rohde C, Starfield B. Primary care physician specialty referral decision making: patient, physician, and health care system determinants. Med Decis Mak. 2006;26:76-85.

39. Judin K. Perception of osteopathy among family physicians in Tallinn, Estonia: Thesis/Dissertation. Maidstone, UK: European School of Osteopathy; 2014.

40. Bundesärztekammer. (Muster-)Berufsordnung für die in Deutschland tätigen Ärztinnen und Ärzte - MBO-Ä 1997: in der Fassung des Beschlusses des 118. Deutschen Ärztetages 2015 in Frankfurt am Main. 2015.

\section{Publisher's Note}

Springer Nature remains neutral with regard to jurisdictional claims in published maps and institutional affiliations.

\footnotetext{
Ready to submit your research? Choose BMC and benefit from:

- fast, convenient online submission

- thorough peer review by experienced researchers in your field

- rapid publication on acceptance

- support for research data, including large and complex data types

- gold Open Access which fosters wider collaboration and increased citations

- maximum visibility for your research: over $100 \mathrm{M}$ website views per year
}

At BMC, research is always in progress.

Learn more biomedcentral.com/submissions 